\title{
Influenza Virus Vaccination in Pediatric Nephrotic Syndrome Induces a Significant Reduction of Relapse and Influenza Virus Infection: A Nationwide Survey
}

\section{Shingo Ishimori}

Department of Pediatrics, Takatsuki General Hospital, Osaka

\section{Takashi Ando}

Renal and Urological Surgery Department, International University of Health and Welfare Hospital, Tochigi

\section{Kaori Kikunaga}

Department of Nephrology, Tokyo Metropolitan Children's Medical Center, Tokyo

\section{Chikako Terano}

Department of Nephrology, Tokyo Metropolitan Children's Medical Center, Tokyo

\section{Mai Sato}

Division of Nephrology and Rheumatology, National Center for Child Health and Development, Tokyo

\section{Fumiyo Komaki}

Department of Pediatrics, Kawasaki Saiwai Clinic, Kanagawa

\section{Riku Hamada}

Department of Nephrology, Tokyo Metropolitan Children's Medical Center, Tokyo

\section{Yuko Hamasaki}

Department of Nephrology, Toho University Faculty of Medicine, Tokyo

\section{Yoshinori Araki}

Department of Pediatrics, National Hospital Organization Hokkaido Medical Center, Sapporo

\section{Yoshimitsu Gotoh}

Department of Pediatric Nephrology, Japanese Red Cross Nagoya Daini Hospital, Nagoya

\section{Koichi Nakanishi}

Department of Child Health and Welfare (Pediatrics), Graduate School of Medicine, University of the Ryukyus

\section{Hitoshi Nakazato}

Department of Pediatrics, Faculty of Life Sciences, Kumamoto University, Kumamoto

\section{Takeshi Matsuyama}

Department of Pediatrics, Fussa Hospital, Tokyo

\section{Kazumoto lijima}

Department of Pediatrics, Kobe University Graduate School of Medicine, Hyogo 


\section{Norishige Yoshikawa}

Clinical Research Center, Takatsuki General Hospital, Osaka

\section{Shuichi Ito}

Department of Pediatrics, Graduate School of Medicine, Yokohama City University, Yokosuka Masataka Honda

Department of Nephrology, Tokyo Metropolitan Children's Medical Center, Tokyo

Kenji Ishikura ( $\boldsymbol{\nabla}$ k-ishikura@umin.ac.jp)

Department of Pediatrics, Kitasato University School of Medicine, Sagamihara

\section{Research Article}

Keywords: Child, Influenza virus infection, Influenza virus vaccination, Nephrotic syndrome, Relapse

Posted Date: July 28th, 2021

DOl: https://doi.org/10.21203/rs.3.rs-750366/v1

License: (c) (1) This work is licensed under a Creative Commons Attribution 4.0 International License. Read Full License 


\section{Abstract}

Although vaccination may precipitate relapses of nephrotic syndrome (NS) in children with idiopathic NS, no data are available regarding NS activity regarding influenza (flu) virus infections and NS relapses after receiving inactivated flu vaccines. We conducted a nationwide study of children aged 6 months to 15 years with idiopathic NS to assess the relationship between NS relapse, flu vaccination, and flu infections. We used a multivariate Poisson regression model (MPRM) to calculate the risk ratio (RR) for flu infection and for NS relapse in children with and without flu vaccination. Data of 306 children were assessed. The MPRM in all 306 children showed a significantly lower RR for flu infection (RR: $0.21,95 \%$ confidence interval [Cl]: $0.11-0.38$ ) and for NS relapse (RR: $0.22,95 \% \mathrm{Cl}: 0.14-0.35)$ in children receiving flu vaccination compared with unvaccinated children. In an additional MPRM only among 102 children receiving flu vaccination, they had a significantly lower risk for NS relapse during the post-vaccination period (RR: $0.31 .95 \% \mathrm{Cl}$ : 017-0.56) compared with the pre-vaccination period. Although our study was observational, based on the favorable results of flu vaccinations regarding flu infections and NS relapse, the vaccine may be recommended for children with NS.

\section{Introduction}

Idiopathic nephrotic syndrome (NS) requires long-term follow-up to manage relapse. Over half of children develop frequently relapsing NS (FRNS) or steroid-dependent NS (SDNS) ${ }^{1}$. To prevent NS relapse, these patients require prolonged steroid therapy and immunosuppressive agents ${ }^{2,3}$. These children have been the state of immunocompromised, in which they have the potential for recurrent or severe infections.

Children with chronic renal disease have a higher risk for severe influenza (flu) infections than healthy children ${ }^{4-6}$. Administering flu vaccines is effective in reducing the prevalence of flu infections and the risk of severe flu infection. KDIGO guidelines suggest that children with NS should receive flu vaccination to reduce the risk of serious infections ${ }^{7}$. Pediatric patients with NS can be protected against flu infection using an inactivated influenza vaccine, even if they are being treated with glucocorticoids or other immunosuppressive drugs ${ }^{4}$. However, as an immunogenic stimulus, immunizations have been reported to trigger NS relapse in children ${ }^{8-13}$. Although inactivated flu vaccines could precipitate NS relapse $\mathrm{e}^{14,15}$, available data regarding the relative risk of NS relapse related to flu vaccines have been scarce until recently. We previously evaluated NS relapse after 104 children with NS received an inactivated subunitantigen influenza virus vaccine ${ }^{16}$. Compared with the NS relapse rate during the pre-vaccination period as a control, the rate within 1 month after receiving flu vaccination was slightly but non-significantly increased (1.19 vs. 1.23 times/person-year, risk ratio: $1.04,95 \%$ confidence interval: $0.82-1.89, p=0.88$ ). Limitations of our previous research included that it was a retrospective study in a single tertiary center and included no data of flu infections. Further studies using a larger sample at multiple centers were needed to investigate not only NS relapses but also flu infections after influenza vaccination.

Here, we report the findings of a nationwide cohort study among Japanese children with idiopathic NS in which we focus on the relationships among NS relapses, flu vaccines, and flu infections. 


\section{Results}

\section{Participant characteristics.}

Overall, 105 of 388 institutions responded to the third questionnaire, and we collected data for 306 children. Figure 1 shows a flow chart of the study design and study populations.

We divided the children into two groups; those who received flu vaccination and those who did not receive flu vaccination. These children's clinical characteristics according to both the second and third questionnaires are shown in Table 1.

\section{Flu infection.}

Table 2 shows that 65 children (21.2\%) developed flu infection between 1 May 2015 and 31 April 2016. Compared with children who received flu vaccination, the flu infection rate among children without flu vaccination was significantly higher ( 12.7 vs. $25.4 \%, p=0.01)$ than in their vaccinated counterparts. The diagnostic method of flu infections and the influenza strain were evaluated in 62 children (68 flu infection cases). All 13 infected children who received flu vaccination and 54 of 55 infected children who did not receive flu vaccination were diagnosed using rapid antigen detection tests and nasopharyngeal swab samples; 6 vaccinated and 25 unvaccinated children had influenza A infection, and 7 vaccinated and 29 unvaccinated children had influenza B infection. Only one unvaccinated patient was clinically diagnosed with flu infection. Figure 2 shows that the seasonal distribution of flu infections during the 2015/16 season was from January to May, and the highest number of flu infections was in February.

\section{Results of multivariate analysis to evaluate the risk ratio for flu infection.}

Table 3 shows the results of multivariate analysis in the 306 children who received and did not receive flu vaccination.

The multivariate Poisson regression model (MPRM) showed statistical evidence of a higher risk ratio for all flu infections in February than in other months (risk ratio: 16.58. 95\% confidence interval: 10.2326.89), and a lower risk ratio for flu infections in children with older age at the onset of NS (risk ratio: 0.90. $95 \%$ confidence interval: $0.84-0.97$ ) and in children who received flu vaccination (risk ratio: 0.21. 95\% confidence interval: $0.11-0.38$ ) (Table 3a). According to flu antigen, the data of risk ratio for influenza B infection were similar to those for all influenza strains (Table 3c); however, the age at onset of NS was not significantly related to influenza A infection (Table 3b). Flu infection in children with NS was not significantly related to sex or history of steroid-resistant NS (SRNS). 


\section{NS relapse.}

In total, 100 children (32.7\%) had NS relapse between 1 May 2015 and 31 April 2016, and there were 190 total NS relapses (Table 2). The proportion of children with NS relapse and the number of NS relapses was slightly higher in children who were not vaccinated than their vaccinated counterparts, but these were not statistically significant. There was no seasonal distribution of NS relapse (Figure 3).

\section{Results of multivariate analysis to evaluate the risk ratio for NS relapse.}

In Table 4, the MPRM for 306 children that received and did not receive flu vaccination showed a significantly lower risk ratio for NS relapse in children who received flu vaccination (risk ratio: $0.22 .95 \%$ confidence interval: $0.14-0.35)$, and a higher risk ratio for NS relapse in children with a history of FRNS or SDNS or SRNS (risk ratio: $2.80 .95 \%$ confidence interval: $1.90-4.11$ ). Sex and age at onset of NS were not independent risk factors for NS relapse in this multivariate analysis.

Table 5 shows the results of the MPRM conducted among the 102 children who received flu vaccination to evaluate the risk of NS relapse during the period after flu vaccination in comparison with before flu vaccination. Taking glucocorticoids at the time of flu vaccination was a risk factor significantly associated with NS relapse (risk ratio: 3.17. 95\% confidence interval: 1.74-5.80). Compared with the prevaccination period, a significantly lower risk for NS relapse during the post-vaccination period (risk ratio: 0.31. 95\% confidence interval: 017-0.56). There was no significant relationship between NS relapse and sex or being on cyclosporine or mizoribine at the time of flu vaccination.

\section{Discussion}

In the present study, we conducted a nationwide cohort study comprising 306 children with idiopathic NS, and showed that children who received flu vaccination had significantly fewer flu infections and NS relapses than those who did not receive flu vaccination. Additionally, the former group showed a significantly lower NS relapse risk during the post-vaccination period compared with the pre-vaccination period.

In this cohort, we examined the relationship among flu vaccination, flu infections, and NS relapses. Multivariate analysis revealed a significantly lower risk ratio for NS relapse in children who received flu vaccination. It has long been considered that vaccination itself can precipitate NS relapse as an immunogenic stimulation; however, the in-depth mechanism of immunogenic pathogenesis has not been elucidated. Several clinical studies have clinically suggested that the varicella vaccine ${ }^{9,10}$, meningococcal $C$ conjugate vaccine ${ }^{11}$, and hepatitis $B$ virus vaccine ${ }^{12}$ trigger NS relapses in children with NS. Nevertheless, that vaccination can precipitate NS relapse is not applicable to all vaccines. The 7valent pneumococcal conjugate vaccine has not been found to be related to the risk of NS relapse in 
association with vaccination ${ }^{17}$. Focusing on flu vaccination in patients with NS, Fernandes et al. described a case report of NS relapse following the use of a monovalent whole-virion inactivated flu vaccine ${ }^{14}$. However, in our nationwide analysis investigating both vaccinated and unvaccinated patients at a number of institutions, we revealed a significant decrease in the NS relapse risk among children who received flu vaccination. Our results provide affirmative findings in comparison with our previous study targeting 104 vaccinated children with NS in a single facility. According to our past and present studies, it may be unnecessary to avoid flu vaccination in children with NS for fear of NS relapse.

This cohort study provided statistical evidence of a lower risk ratio for flu infection among children who receive flu vaccination. It has been reported that upper respiratory viral infections in pediatric patients induce NS relapse. McDonald et al. showed that respiratory viruses such as respiratory syncytial virus, parainfluenza virus, varicella zoster virus, and adenovirus are associated with NS exacerbation and relapse in children ${ }^{18}$. Similarly, NS relapse following influenza virus infection has been reported, including infection with the 2009 pandemic H1N1 virus ${ }^{18,19}$. Therefore, reducing flu infections in children with NS is desirable. The effectiveness of flu vaccination in pediatric patients with NS is proven serologically, with adequate antibody responses at 6 months post-vaccination ${ }^{15}$. In addition, our survey demonstrated the clinical efficacy of flu vaccination among children with NS in preventing flu infections.

We found that being on glucocorticoids when receiving flu vaccination was a risk factor significantly associated with NS relapse among children with NS. Pediatric patients treated with steroids at the time of flu vaccination would means on the state soon after the last NS relapse. Thus, NS relapses might be easy to trigger in children who are treated with steroids at the time of receiving flu vaccination owing to taking glucocorticoids being a marker of recent NS relapse.

The present study has several limitations. First, bias existed between children with and without flu vaccination, with a significant difference in history of FRNS among children. We could not address these biases completely, even with adjustment in multivariate analysis, because this was an uncontrolled study. Each physician may have adopted the type of NS as a selection criterion in their decision to recommend flu vaccination to patients. Regardless, we evaluated many influencing factors for flu infections and NS relapses so as to adjust for confounding as much as possible. Nevertheless, we should recognize this difference as confounding in the present analysis and consider that the results regarding a lower risk for NS relapse in children who receive flu vaccination cannot be applied to all children with NS. Moreover, we expect that some unrecognized bias existed between children with and without flu vaccination. Second, we could not collect data of all events during the observation period. With further details, including data of whether fever, rhinorrhea, coughing, and vomiting resulting from both bacterial and viral infections triggered NS relapse, we might be able to conclude that flu vaccination could prevent NS relapse in terms of direct management of various infections. Third, we had no data regarding the precise interval between the timing of flu vaccination and NS relapses in each individual. Because the side effects of the inactivated subunit-antigen flu vaccine generally occur within 2-4 weeks of administration, NS relapses within 1 month after vaccination were possibly triggered by vaccination itself. However, differences in the 
state of NS activity during the pre- and post-vaccination periods are worth evaluating to determine whether there is a significantly lower risk for NS relapse in the post-vaccination period as compared with the pre-vaccination period. Finally, vaccine policies in each center are not uniform. Some facilities have a policy of administering inactivated subunit-antigen flu vaccines to children with NS depending on their steroid dose, and other centers have different policies depending on the period from onset of NS or last NS relapse.

In conclusion, although our study was observational, based on the favorable results of flu vaccination against flu infection and NS relapse, the vaccine may be recommended for children with NS regardless of immunosuppressant use at the time of vaccination.

\section{Methods}

\section{Study design and populations.}

The Japanese Pediatric Survey Holding Information of Nephrotic Syndrome (JP-SHINE) study, a nationwide cohort study, was established by the Japanese Study Group of Renal Disease in Children. The first survey was sent on 4 April 2014 to 1860 institutions throughout Japan, including all universities and children's and general hospitals with more than 20 beds. Patients were eligible if they were newly diagnosed with idiopathic NS between 1 January 2010 and 31 December 2012, were between 6 months and 15 years old, and if they had been treated for up to 3 years during this time. Patients with congenital nephrotic syndrome or nephrotic syndrome secondary to nephritis were excluded. The first questionnaire, which was designed to record the number of children with idiopathic NS at each institution and their basic information, was sent to 1860 institutions. Of these, 1050 institutions (56.5\%) responded to the first questionnaire $^{20}$. The second questionnaire regarding patients who fulfilled the eligibility criteria was sent to 388 institutions and recorded information including patients' basic characteristics, renal biopsy, idiopathic NS complications, steroid therapy side effects, and prognosis. We collected data for 999 patients ${ }^{21}$. In the present study, we recorded age when the patient received the first inactivated subunitantigen flu vaccine, the total number of flu vaccinations received, total number of flu infections, total number of NS relapses, rituximab (RTX) use at the first flu vaccination, and immunosuppressant use at the first flu vaccination (cyclosporine, mycophenolate mofetil, mizoribine, cyclophosphamide, tacrolimus) between 1 May 2015 and 31 April 2016.

\section{Definitions}

In the present study, the definitions of general conditions in pediatric NS were according to clinical guidelines issued by the Japanese Society for Pediatric Nephrology ${ }^{22,23}$. Idiopathic NS in children was defined as hypoalbuminemia (serum albumin levels $\leq 2.5 \mathrm{~g} / \mathrm{dL}$ ) and severe proteinuria $\left(\geq 40 \mathrm{mg} / \mathrm{h} / \mathrm{m}^{2}\right.$ in pooled nighttime urine or an early morning urine protein creatinine $(\mathrm{Cr})$ ratio $>2.0 \mathrm{~g} / \mathrm{g} \mathrm{Cr}$ ). Complete remission was defined as a urine protein creatinine ratio $<0.2 \mathrm{~g} / \mathrm{g}$ Cr or $\leq$ negative protein on early 
morning urine dipstick testing for 3 consecutive days. SSNS was defined as complete remission in $<4$ weeks after starting daily prednisolone therapy. NS relapse was defined as $\geq 3+$ protein on early morning urine dipstick testing for 3 consecutive days. FRNS was defined as two or more relapses within 6 months after initial response or four or more relapses within any consecutive 12-month period. SDNS was defined as two consecutive relapses occurring during steroid therapy or within 2 weeks of treatment cessation. SRNS was defined as the absence of complete remission after a 4-week course of oral prednisolone 60 $\mathrm{mg} / \mathrm{m}^{2} /$ day. RTX therapy duration was defined as the period from the day of rituximab administration to the day of B-cell recovery (CD19 + B-cell count $\geq 1 \%$ of total lymphocytes).

Influenza virus infection was diagnosed using rapid antigen detection tests with a nasopharyngeal swab sample or was clinically diagnosed by an attending pediatrician. In Japan, children younger than 13 years old generally receive flu vaccination twice per year and those over 13 years old are vaccinated once per year. In children who received two vaccinations in the same year, we defined the "first flu vaccine" as their first vaccination of the two. Antigen strains in inactivated flu vaccines between 2015 and 2016 were A/California/7/2009 (X-179A) (H1N1) pdm09, A/Switzerland/9715293/2013 NIB-88 (H3N2), B/Phuket/3073/2013, and B/Texas/2/2013.

\section{Steroid therapy and immunosuppressants.}

We adopted the modified International Study of Kidney Diseases in Children protocol, as shown in the Japanese pediatric idiopathic NS guideline ${ }^{2,23-25}$, and $63 \%$ of children were treated with the protocol, as follows. The initial 8-week treatment protocol was $60 \mathrm{mg} / \mathrm{m}^{2} /$ day prednisolone (maximum daily dosage $60 \mathrm{mg}$ ) for 4 weeks, followed by $40 \mathrm{mg} / \mathrm{m}^{2} /$ day (maximum daily dosage $40 \mathrm{mg}$ ) on alternate days for 4 weeks ${ }^{21}$. Thirty percent of children were treated with the prolonged protocol, which was initial treatment using a prolonged protocol of $60 \mathrm{mg} / \mathrm{m}^{2} /$ day prednisolone (maximum daily dosage $60 \mathrm{mg}$ ) for 4 weeks, followed by $40 \mathrm{mg} / \mathrm{m}^{2} /$ day (maximum daily dosage $40 \mathrm{mg}$ ) on alternate days, tapered over 2-6 months. Treatment in the remaining $7 \%$ of children was unknown. Immunosuppressants used between 1 May 2015 and 31 April 2016 were cyclosporine in 55\%, mizoribine in 39\%, cyclophosphamide in 13\%, mycophenolate mofetil in $11 \%$, RTX in $11 \%$, and tacrolimus in $2 \%$ of patients.

\section{Ethics.}

This study was conducted according to the principles of the Declaration of Helsinki and following the ethical guidelines for Medical and Health Research Involving Human Subjects of the Ministry of Health, Labour and Welfare in Japan. Yokohama City University Hospital's central ethics review board approved this study (approval number: 1509001). This ethics committee clearly stated that the researchers did not need to obtain informed consent, because complete data in this study were collected from patient medical records. In accordance with this statement, informed consent was not required from patients or their parents in this study. According to the guidelines and the institutional ethics review board for the 
patients' benefit, the protocol was displayed publicly in a poster at each hospital, and each patient or their family had the opportunity to refuse to be included in this analysis.

\section{Statistical analysis.}

We used ttests for continuous values and the chi-square and Fisher's exact test for categorical values. All data were expressed as mean \pm standard deviation or number (percentage). We used a MPRM for children who received or did not receive flu vaccination to calculate the risk ratio for flu infection, adjusted for receiving or not receiving flu vaccination, sex, age at NS onset, history of FRNS or SDNS or SRNS, flu infection in February or another month, and the risk ratio for NS relapse adjusted for whether the patients received flu vaccination, sex, age at NS onset, and history of FRNS or SDNS or SRNS. To evaluate the risk of NS relapse after flu vaccination, we used the MPRM only among children who received flu vaccination to calculate the risk ratio for NS relapse, adjusted for the post-vaccination period or pre-vaccination period, sex, and whether the patient was taking glucocorticoids or various immunosuppressants at flu vaccination. A $P$-value $<0.05$ was considered statistically significant. We used SAS software package for Windows, release 9.4 (SAS Institute Inc. Cary, NC, USA) to perform all statistical analyses.

Data are available upon reasonable request.

\section{Declarations}

\section{Acknowledgments}

This work was sponsored by the Japanese Study Group of Renal Disease in Children, Asahi Kasei Pharma, Astellas Pharma, Fuso Pharmaceutical Industries, JMS, Novartis Pharma and Zenyaku Kogyo. The authors would like to thank all the hospitals, institutions and pediatricians for their cooperation in this study. The authors would like to thank Edanz Group (https://en-authorservices.edanz.com/ac) for the English language review.

\section{Author contributions}

All authors contributed to the following: 1 Conception or design, or analysis and interpretation of data, or both, 2 Drafting the article or revising it, 3 Providing intellectual content of critical importance to the work described, 4 Final approval of the version to be published. In particular, S.Is. prepared the manuscript. K.K., C.T., M.S., F.K., R.H. and Y.H. collected the clinical data. T.A. conducted the statistical analysis. Y.A., Y.G., K.N., H.N., T.M., K.II., N.Y., S.It. and M.H. revised the article. K.Is. oversaw the work as the corresponding author and helped to revise the article.

\section{Additional information}




\section{Competing Interests Statement}

S.Is., T.A., K.K., C.T., M.S., F.K., R.H., Y.A., Y.G., K.N., H.N., T.M., N.Y. and M.H. have no financial relationships relevant to this article to disclose. Y.H. belonged to an endowed department sponsored by Asahi Kasei Pharma Corporation, Novartis Pharma K. K., Chugai Pharmaceutical Co., and Astellas Pharma (until 28 February 2018). K.li. received grants from Astellas Pharma, Daiichi Sankyo, and Zenyaku Kogyo. S.It. received grants from Asahi Kasei Pharma Corporation, Astellas Pharma, Chugai Pharmaceutical Co., Japan Blood Products Organization, Pfizer, and Teijin; and lecture and/or consulting fees from Asahi Kasei Pharma Corporation, Astellas Pharma, Chugai Pharmaceutical Co., Novartis Pharma K. K., and Zenyaku Kogyo. K.Is. received grants from Astellas Pharma, Daiichi Sankyo, and Zenyaku Kogyo.

Correspondence and requests for materials should be addressed to K.Is.

\section{References}

1. Eddy, A. A. \& Symons, J. M. Nephrotic syndrome in childhood. Lancet, 362, 629-639 https://doi.org/http:// (2003).

2. Tarshish, P., Tobin, J. N., Bernstein, J. \& Edelmann, C. M. Jr. Prognostic significance of the early course of minimal change nephrotic syndrome: report of the International Study of Kidney Disease in Children. J Am Soc Nephrol, 8, 769-776 https://doi.org/http:// (1997).

3. Sinha, A. et al. Disease course in steroid sensitive nephrotic syndrome. Italian Pediatr, 49, 881-887 https://doi.org/http:// (2012).

4. Steele, R. W. Current status of vaccines and immune globulins for children with renal disease. Pediatr Nephrol, 8, 7-10 https://doi.org/http:// (1994).

5. Beyer, W. E. et al. Effect of immunomodulator thymopentin on impaired seroresponse to influenza vaccine in patients on hemodialysis. Nephron, 54, :296-301 https://doi.org/http:// (1990).

6. Nikoskelainen, J., Vaananen, P., Forsstrom, J. \& Kasanen, A. Influenza vaccination in patients with chronic renal failure. Scand J Infect Dis, 14, 245-251 https://doi.org/http:// (1982).

7. KDIGO clinical practice guideline for glomerulonephritis. Chapter 3: Steroid-sensitive nephritic syndrome in children. Kidney Int, Suppl2, 163-171 (2012).

8. Szajner-Milart, I., Zajaczkowska, M., Zinkiewicz, Z., Borzecka, H. \& Majewski, M. Efficacy of vaccination against viral hepatitis type $B$ in children with the nephrotic syndrome. Ann univ Mariae Curie Sklodowska Med, 58, 402-408 (2003).

9. Furth, S. L. et al. Varicella vaccination in children with nephrotic syndrome: a report of the Southwest Pediatric Nephrology Study Group. J Pediatr, 142, 145-148 https://doi.org/http:// (2003).

10. Alpay, H., Yildiz, N., Onar, A., Temizer, H. \& Ozcay, S. Varicella vaccination in children with steroidsensitive nephrotic syndrome. Pediatr Nephrol, 17, 181-183 (2002). http://doi: 10.1007/s00467-0010789-7 
11. Abeyagunawardena, A. S., Goldblatt, D., Andrews, N. \& Trompeter, R. S. Risk of relapse after meningococcal C conjugate vaccine in nephrotic syndrome. Lancet, 362, 449-450 (2003). http://doi: 10.1016/s0140-6736(03)14072-x

12. Yildiz, N. et al. Hepatitis B virus vaccination in children with steroid sensitive nephrotic syndrome: immunogenicity and safety? Vaccine, 31, 3309-3312 https://doi.org/http:// (2013).

13. Liakou, C. D. et al. Safety and immunogenicity of booster immunization with 7-valent pneumococcal conjugate vaccine in children with idiopathic nephrotic syndrome. Vaccine, 32, 1394-1397 https://doi.org/http:// (2014).

14. Fernandes, P., Jorge, S. \& Lopes, J. A. Relapse of nephrotic syndrome following the use of 2009 pandemic influenza A (H1N1) vaccine. Am J Kidney Dis, 56, 185-186 (2010). http://doi: 10.1053/j.ajkd.2010.04.011

15. Poyrazoglu, H. M., Dusunsel, R., Gunduz, Z., Patiroglu, T. \& Koklu, S. Antibody response to influenza A vaccination in children with nephrotic syndrome. Ped Nephrol, 19, 57-60 (2004). http://doi: 10.1007/s00467-003-1301-3

16. Ishimori, S. et al. Influenza virus vaccination in children with nephrotic syndrome: insignificant risk of relapse. Clin Exp Nephrol, 27, 1-8 (2020). http://doi: 10.1007/s10157-020-01930-8

17. Liakou, C. D. et al. Safety and immunogenicity of booster immunization with 7-valent pneumococcal conjugate vaccine in children with idiopathic nephrotic syndrome. Vaccine, 32, 1394-1397 https://doi.org/http:// (2014).

18. MacDonald, N. E., Wolfish, N., Mclaine, P., Phipps, P. \& Rossier, E. Role of respiratory viruses in exacerbations of primary nephrotic syndrome. J Pediatr, 108, 378-382 (1986). http://doi: 10.1016/s0022-3476(86)80876-9

19. Kim, S. R. et al. Relapse of minimal change disease following infection with the 2009 pandemic influenza (H1N1) virus. Clin Exp Nephrol, 16, 329-332 (2012). http://doi: 10.1007/s10157-011-05626

20. Kikunaga, K. et al. High incidence of idiopathic nephrotic syndrome in East Asian children: a nationwide survey in Japan (JP-SHINE study). Clin Exp Nephrol, 21, 651-657 (2017). http://doi: 10.1007/s10157-016-1319-z

21. Sato, M. et al. Prognosis and acute complications at the first onset of idiopathic nephrotic syndrome in children: a nationwide survey in Japan (JP-SHINE study). Nephrol Dial Transplant, 36, 475-481 https://doi.org/http:// (2021).

22. Ishikura, K. et al. Clinical practice guideline for pediatric idiopathic nephrotic syndrome 2013: medical therapy. Clin Exp Nephrol, 19, 6-33 (2015). http://doi: 10.1007/s10157-014-1030-x

23. Kaku, Y. et al. Clinical practice guideline for pediatric idiopathic nephrotic syndrome 2013: general therapy. Clin Exp Nephrol, 19, 34-53 (2015). http://doi: 10.1007/s10157-014-1031-9

24. van Husen, M. \& Kemper, M. J. New therapies in steroid-sensitive and steroid-resistant idiopathic nephrotic syndrome. Pediatr Nephrol, 26, 881-892 (2011). http://doi: 10.1007/s00467-010-1717-5 
25. Yoshikawa, N. et al. A multicenter randomized trial indicates initial prednisolone treatment for childhood nephrotic syndrome for two months is not inferior to six-month treatment. Kidney Int, 87, 225-232 https://doi.org/http:// (2015).

\section{Tables}


Table 1

Clinical characteristics of the patients

for NS relapses

$\begin{array}{llll}\text { All }(\mathrm{N}=306) & \begin{array}{l}\text { Flu } \\ \text { vaccination } \\ (\mathrm{N}=102)\end{array} & \begin{array}{l}\text { No flu } \\ \text { vaccination } \\ (\mathrm{N}=204)\end{array} & \begin{array}{l}\mathrm{p} \\ \text { value }\end{array}\end{array}$

Background; second questionnaire

\begin{tabular}{|c|c|c|c|c|}
\hline Age at onset of NS (years) & $6.0 \pm 4.1$ & $5.6 \pm 4.0$ & $6.2 \pm 4.2$ & 0.26 \\
\hline Boy : Girl, $n(\%)$ & $\begin{array}{l}215: 91 \\
(70.3 \%: 29.7 \\
\%)\end{array}$ & $\begin{array}{l}76: 26 \\
(74.5 \%: 25.5 \\
\%)\end{array}$ & $\begin{array}{l}139: 65 \\
(68.1 \%: 31.9 \\
\%)\end{array}$ & 0.25 \\
\hline Gestational week * & $38.7 \pm 2.3$ & $38.7 \pm 2.2$ & $38.7 \pm 2.3$ & 0.48 \\
\hline Birth weight $^{\dagger}$ & $2945 \pm 497$ & $2983 \pm 507$ & $2925 \pm 491$ & 0.71 \\
\hline Family history of NS, $n(\%)^{\ddagger}$ & $9(3.0 \%)$ & $1(1.0 \%)$ & $8(4.0 \%)$ & 0.28 \\
\hline History of allergy, $n(\%) \S$ & $114(38.4 \%)$ & $44(43.6 \%)$ & $70(35.7 \%)$ & 0.19 \\
\hline Asthma & $36(12.1 \%)$ & $11(10.9 \%)$ & $25(12.8 \%)$ & 0.64 \\
\hline Atopic dermatitis & $34(11.4 \%)$ & $12(11.9 \%)$ & $22(11.2 \%)$ & 0.87 \\
\hline Allergic rhinitis & $56(18.9 \%)$ & $22(21.8 \%)$ & $34(17.3 \%)$ & 0.35 \\
\hline Allergic conjunctivitis & $8(2.7 \%)$ & $4(4.0 \%)$ & $4(2.0 \%)$ & 0.45 \\
\hline Food allergy & $28(9.4 \%)$ & $9(8.9 \%)$ & $19(9.7 \%)$ & 0.83 \\
\hline Other & $6(2.0 \%)$ & $2(2.0 \%)$ & $4(2.0 \%)$ & 1.0 \\
\hline Hematuria at onset of NS, $n(\%) \|$ & $95(31.5 \%)$ & $35(35.0 \%)$ & $60(29.7 \%)$ & 0.35 \\
\hline $\begin{array}{l}\text { Past history of frequent-relapsing } \\
\text { NS, } n(\%)\end{array}$ & $147(48.0 \%)$ & $39(38.2 \%)$ & $108(52.9 \%)$ & 0.015 \\
\hline $\begin{array}{l}\text { Past history of steroid-dependent } \\
\text { NS, } n(\%)\end{array}$ & $134(43.8 \%)$ & $38(37.3 \%)$ & $96(47.1 \%)$ & 0.1 \\
\hline $\begin{array}{l}\text { Past history of steroid-resistant NS, } \\
n(\%)\end{array}$ & $29(9.6 \%)$ & $9(8.9 \%)$ & $20(10.0 \%)$ & 0.76 \\
\hline Renal biopsy, $n(\%){ }^{* *}$ & $163(54.3 \%)$ & $50(50.0 \%)$ & $113(55.6 \%)$ & 0.45 \\
\hline Classification of renal histology & & & & 0.25 \\
\hline Minimal change & $132(81.0 \%)$ & $40(80.0 \%)$ & $92(81.4 \%)$ & \\
\hline \multirow[t]{2}{*}{ Focal segmental glomerular } & $14(8.6 \%)$ & $7(14.0 \%)$ & $7(6.2 \%)$ & \\
\hline & Page $13 / 20$ & & & \\
\hline
\end{tabular}


sclerosis

Diffuse mesangial proliferation

$9(5.5 \%)$

$0(0.0 \%)$

$9(8.0 \%)$

Other

$8(4.9 \%)$

$3(6.0 \%)$

$5(4.4 \%)$

NS; nephrotic syndrome, Flu; influenza virus, FRNS; frequently relapsing NS, SDNS; steroid-dependent NS, SRNS; steroid-resistant nephrotic syndrome,

* Evaluated 246 children with data for gestational weeks. † Evaluated 254 children with data of birth weight. $\ddagger$ Evaluated 299 children with data for family history of

SRNS. § Evaluated 297 children with data for history of allergy. || Evaluated 302 children with data for hematuria at onset of NS. 9 Evaluated 301 children with data of

past history of SRNS. ** Evaluated 300 children with data of renal biopsy.

Table 2

Flu infections and nephrotic syndrome relapses

for NS relapses

\begin{tabular}{|c|c|c|c|c|}
\hline & $\begin{array}{l}\text { All } \\
(N=306)\end{array}$ & $\begin{array}{l}\text { Flu } \\
\text { vaccination } \\
(\mathrm{N}=102)\end{array}$ & $\begin{array}{l}\text { No flu } \\
\text { vaccination } \\
(\mathrm{N}=204)\end{array}$ & $\begin{array}{l}\mathrm{p} \\
\text { value }\end{array}$ \\
\hline Total number of flu infected patient, $n(\%)$ & $\begin{array}{l}65(21.2 \\
\%)\end{array}$ & $13(12.7 \%)$ & $52(25.4 \%)$ & 0.01 \\
\hline Total number of flu infection, times * & 67 & 13 & 54 & 1.0 \\
\hline $\begin{array}{l}\text { Total number of antigen A flu infection, } \\
\text { times }(\%)\end{array}$ & $\begin{array}{l}31(46.3 \\
\%)\end{array}$ & $6(46.2 \%)$ & $25(46.3 \%)$ & \\
\hline $\begin{array}{l}\text { Total number of antigen B flu infection, } \\
\text { times (\%) }\end{array}$ & $\begin{array}{l}31(53.7 \\
\%)\end{array}$ & $7(53.4 \%)$ & $29(53.7 \%)$ & \\
\hline Number of children had NS relapse, $n(\%)$ & $\begin{array}{l}100(32.7 \\
\%)\end{array}$ & $30(29.4 \%)$ & $70(34.3 \%)$ & 0.39 \\
\hline $\begin{array}{l}\text { Total number of NS relapse, times } \\
\text { (times/person-year) }\end{array}$ & $\begin{array}{l}190 \\
(0.62)\end{array}$ & $48(0.47)$ & $142(0.70)$ & 0.39 \\
\hline
\end{tabular}

NS; nephrotic syndrome, Flu; influenza virus, * Of 65 children with flu infection, 67 times diagnosed using rapid antigen detection tests with nasopharyngeal swab samples were evaluated. 
Table 3

Risk ratio for flu infection in 306 children who received and did not receive flu vaccination (multivariate analysis)

(a) all influenza infections

\begin{tabular}{llll}
\hline & \multicolumn{3}{l}{ for all flu infection } \\
\hline Variable & $\begin{array}{c}\text { Risk } \\
\text { ratio }\end{array}$ & $\begin{array}{l}95 \% \text { Confidence } \\
\text { interval }\end{array}$ & P value \\
\hline $\begin{array}{l}\text { Received flu vaccines } \\
\text { (reference: no vaccines) }\end{array}$ & 0.21 & $0.11-0.38$ & $<0.0001$ \\
\hline $\begin{array}{l}\text { Female } \\
\text { (reference: male) }\end{array}$ & 1.49 & $0.92-2.42$ & 0.10 \\
\hline $\begin{array}{l}\text { Age at onset of NS } \\
\text { Past history of FRNS or SDNS or SRNS } \\
\text { (reference: no history of FRNS or SDNS or }\end{array}$ & 0.90 & $0.84-0.97$ & 0.003 \\
\hline $\begin{array}{l}\text { SRNS) } \\
\text { On February } \\
\text { (reference: other months) }\end{array}$ & 0.77 & $0.47-1.23$ & 0.27 \\
\hline
\end{tabular}

NS; nephrotic syndrome, Flu; influenza virus, FRNS; frequently relapsing NS, SDNS; steroid-dependent NS,

SRNS; steroid-resistant nephrotic syndrome. 
Table 3

(b) influenza A infections

for flu A infection

\begin{tabular}{|c|c|c|c|}
\hline Variable & $\begin{array}{l}\text { Risk } \\
\text { ratio }\end{array}$ & $\begin{array}{l}95 \% \text { Confidence } \\
\text { interval }\end{array}$ & $P$ value \\
\hline $\begin{array}{l}\text { Received flu vaccines } \\
\text { (reference: no vaccines) }\end{array}$ & 0.21 & $0.09-0.50$ & 0.0004 \\
\hline $\begin{array}{l}\text { Female } \\
\quad \text { (reference: male) }\end{array}$ & 1.78 & $0.89-3.58$ & 0.10 \\
\hline Age at onset of NS & 0.91 & $0.83-1.00$ & 0.053 \\
\hline $\begin{array}{l}\text { Past history of FRNS or SDNS or SRNS } \\
\text { (reference: no history of FRNS or SDNS or } \\
\text { SRNS) }\end{array}$ & 0.53 & $0.29-1.05$ & 0.07 \\
\hline $\begin{array}{l}\text { On February } \\
\text { (reference: other months) }\end{array}$ & 19.80 & $9.64-40.65$ & $<0.0001$ \\
\hline
\end{tabular}

NS; nephrotic syndrome, Flu; influenza virus, FRNS; frequently relapsing NS, SDNS; steroid-dependent NS, SRNS; steroid-resistant nephrotic syndrome.

Table 3

(c) influenza B infections

\begin{tabular}{llll}
\hline & \multicolumn{2}{l}{ for flu B infection } & \\
\hline Variable & $\begin{array}{c}\text { Risk } \\
\text { ratio }\end{array}$ & $\begin{array}{l}95 \% \text { Confidence } \\
\text { interval }\end{array}$ & P value \\
\hline $\begin{array}{l}\text { Received flu vaccines } \\
\text { (reference: no vaccines) }\end{array}$ & 0.20 & $0.09-0.46$ & 0.0002 \\
\hline $\begin{array}{l}\text { Female } \\
\text { (reference: male) }\end{array}$ & 1.27 & $0.65-2.50$ & 0.48 \\
\hline $\begin{array}{l}\text { Age at onset of NS } \\
\text { Past history of FRNS or SDNS or SRNS } \\
\text { (reference: no history of FRNS or SDNS or }\end{array}$ & 0.90 & $0.82-0.99$ & 0.027 \\
\hline \begin{tabular}{l} 
SRNS) \\
\hline $\begin{array}{l}\text { On February } \\
\text { (reference: other months) }\end{array}$
\end{tabular} & 1.08 & $0.54-2.14$ & 0.83 \\
\hline
\end{tabular}

NS; nephrotic syndrome, Flu; influenza virus, FRNS; frequently relapsing NS, SDNS; steroid-dependent NS, SRNS; steroid-resistant nephrotic syndrome. 
Table 4

Risk ratio for nephrotic syndrome relapse in 306 children who received and did not receive flu vaccination (multivariate analysis)

\begin{tabular}{llll}
\hline & for NS relapse & \\
\hline Variable & $\begin{array}{c}\text { Risk } \\
\text { ratio }\end{array}$ & $\begin{array}{l}95 \% \text { Confidence } \\
\text { interval }\end{array}$ & P value \\
\hline $\begin{array}{l}\text { Received flu vaccines } \\
\text { (reference: no vaccines) }\end{array}$ & 0.22 & $0.14-0.35$ & $<0.0001$ \\
\hline $\begin{array}{l}\text { Female } \\
\text { (reference: male) }\end{array}$ & 1.08 & $0.80-1.47$ & 0.61 \\
\hline Age at onset of NS & 0.99 & $0.95-1.02$ & 0.41 \\
\hline $\begin{array}{l}\text { Past history of FRNS or SDNS or SRNS } \\
\text { (reference: no history of FRNS or SDNS or }\end{array}$ & 2.80 & $1.90-4.11$ & $<0.0001$ \\
\hline \begin{tabular}{l} 
SRNS) \\
\hline
\end{tabular} & & & \\
\hline
\end{tabular}

NS; nephrotic syndrome, Flu; influenza virus, FRNS; frequently relapsing NS, SDNS; steroid-dependent NS, SRNS; steroid-resistant nephrotic syndrome. 
Table 5

Risk ratio for nephrotic syndrome relapse among 102 children who received flu vaccination (multivariate analysis)

\begin{tabular}{llll}
\hline & \multicolumn{2}{l}{ for NS relapse } & \\
\hline Variable & $\begin{array}{c}\text { Risk } \\
\text { ratio }\end{array}$ & $\begin{array}{l}95 \% \text { Confidence } \\
\text { interval }\end{array}$ & P value \\
\hline $\begin{array}{l}\text { Post vaccination period } \\
\text { (reference: pre vaccination period) }\end{array}$ & 0.31 & $0.17-0.56$ & $<0.0001$ \\
\hline $\begin{array}{l}\text { Female } \\
\text { (reference: male) }\end{array}$ & 0.81 & $0.36-1.86$ & 0.62 \\
\hline $\begin{array}{l}\text { The state of being on medicines at flu } \\
\text { vaccinations }\end{array}$ & & & 0.0002 \\
\hline $\begin{array}{l}\text { being on glucocorticoid } \\
\text { (reference: no glucocorticoid) }\end{array}$ & 3.17 & $1.74-5.80$ & 0.55 \\
\hline $\begin{array}{l}\text { being on Cyclosporine } \\
\text { (reference: no Cyclosporine) }\end{array}$ & 0.82 & $0.43-1.58$ & 0.23 \\
\hline $\begin{array}{l}\text { being on Mizoribine } \\
\text { (reference: no Mizoribine) }\end{array}$ & 0.56 & $0.22-1.44$ & \\
\hline
\end{tabular}

NS; nephrotic syndrome, Flu; influenza virus

Figures

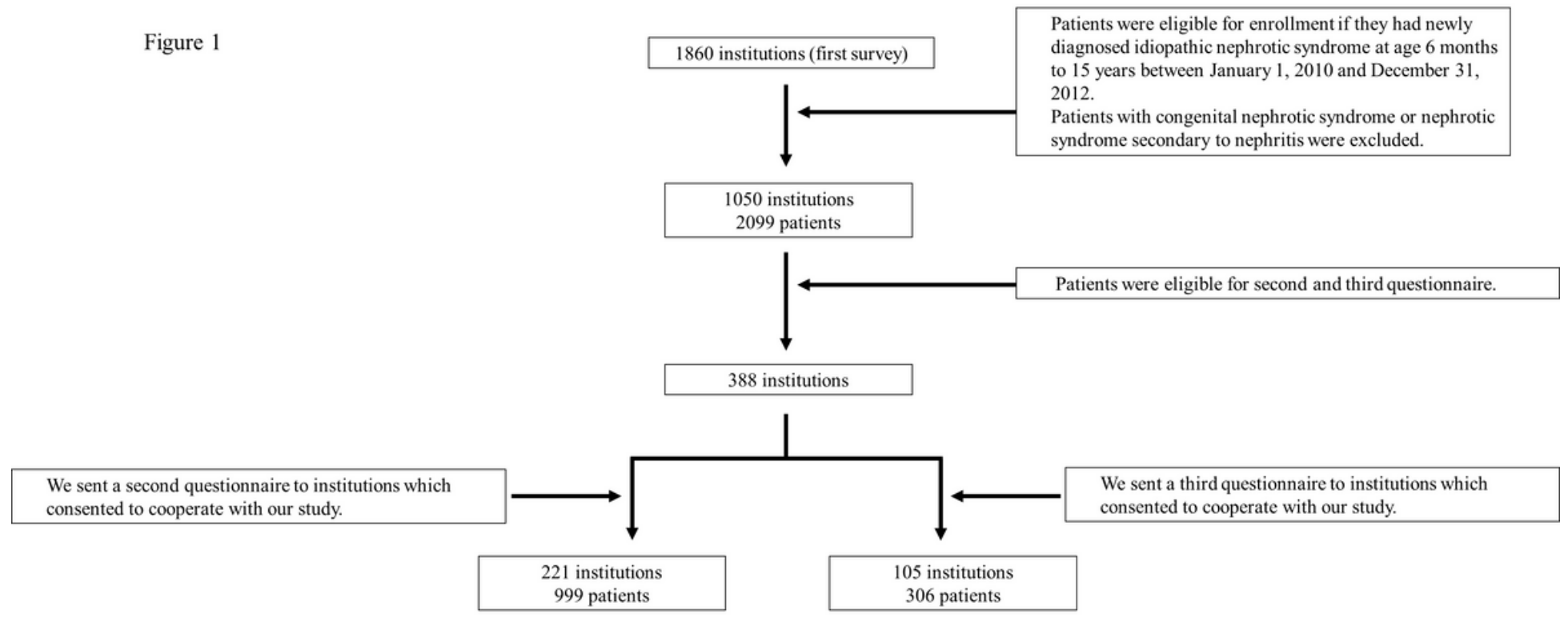

Figure 1 
Flow chart of study design and populations Of 388 institutions, 105 responded to the third questionnaire and data were collected for 306 children.

\section{Figure 2}

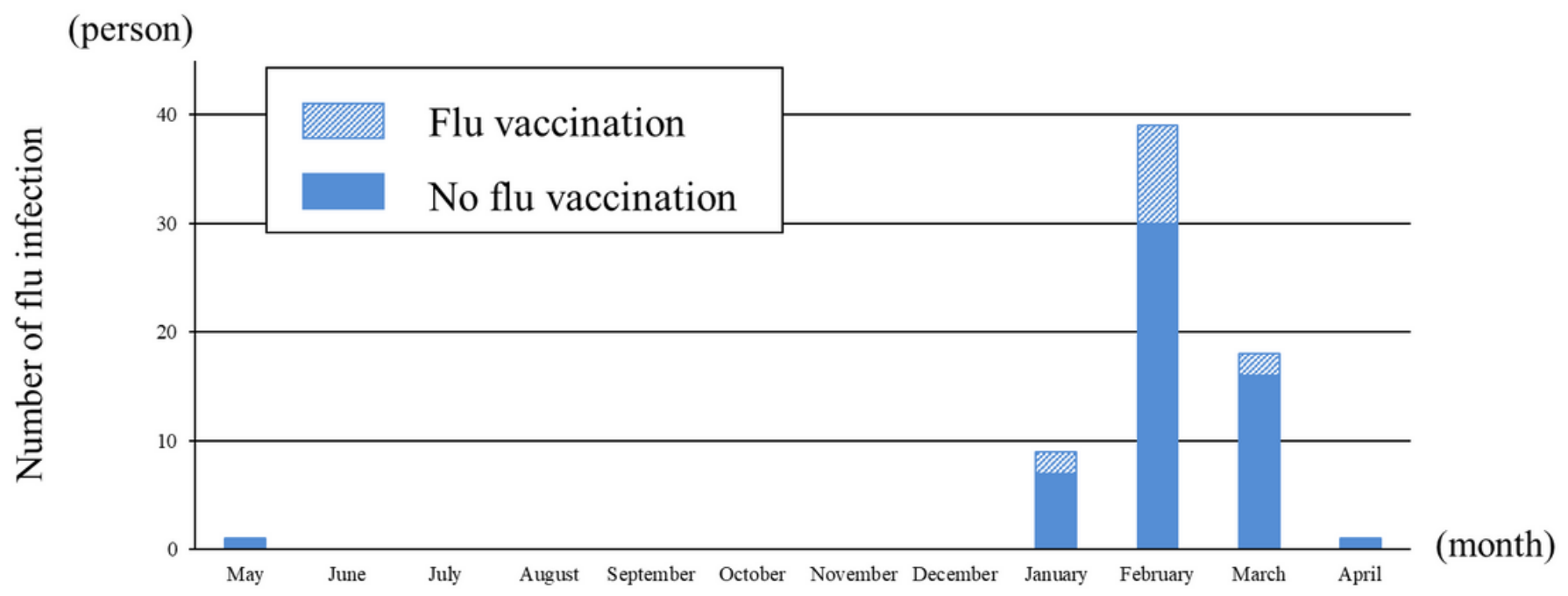

\section{Figure 2}

Number of influenza virus infections Seasonal distribution of influenza (flu) infections was from January to May. February had the highest number of flu infections. 
Figure 3

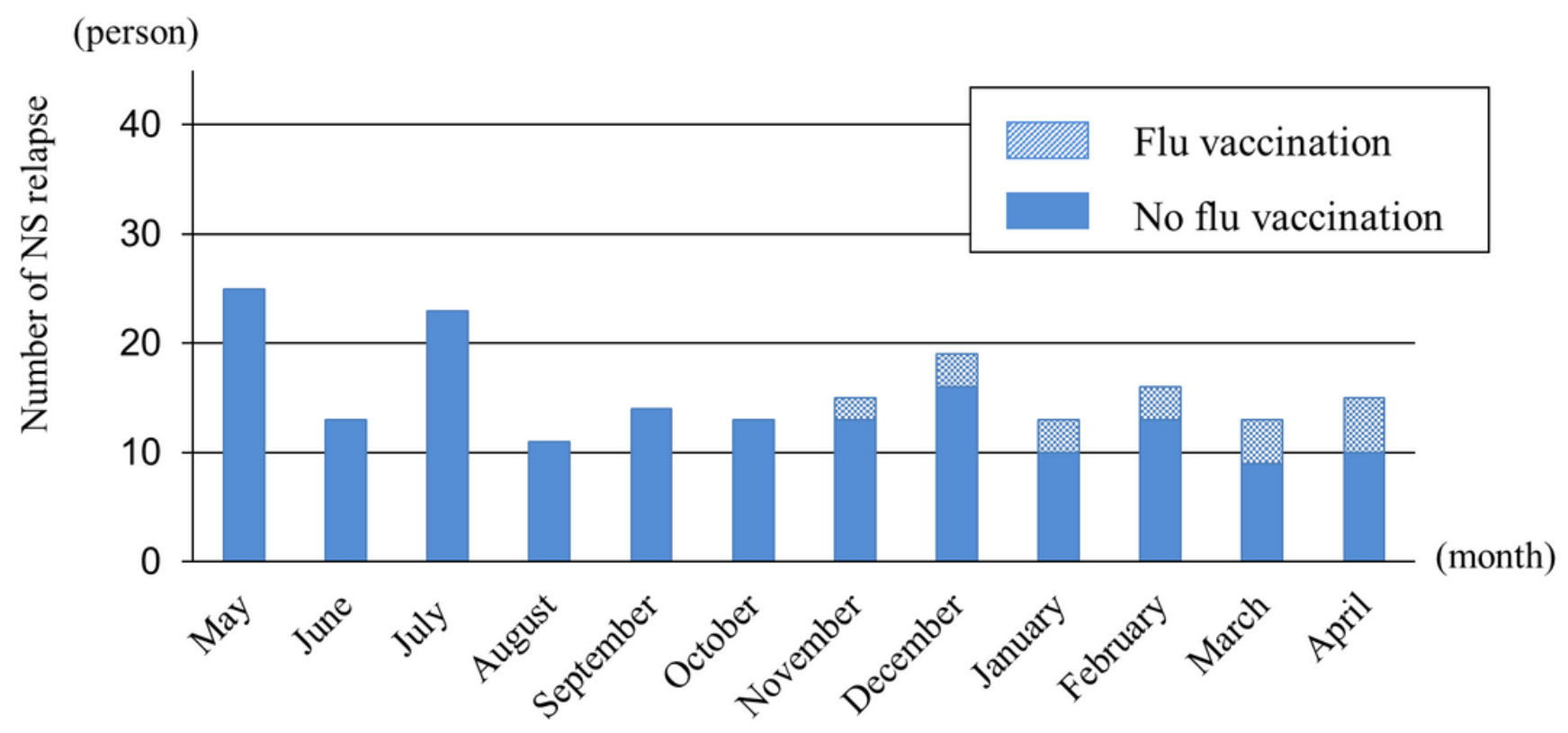

Figure 3

Number of nephrotic syndrome (NS) relapses There was no seasonal distribution of NS relapse. 